\title{
Graduate Students' Perceived Needs and Preferences for Supervisor Written Feedback for Thesis Writing
}

\author{
Yenus Nurie \\ Bahir Dar University \\ Correspondence concerning this article should be addressed to Yenus Nurie, Faculty of Humanities, Bahir \\ Dar University, P.O. Box 79, Ethiopia. Email: yenusn@gmail.com
}

\begin{abstract}
A plethora of previous research has explored students' preferences for written feedback from teachers to respond to students' writing in the classroom. However, little or no research has investigated graduate students' needs and preferences regarding written feedback provided by their supervisors in response to thesis writing. This study examined the feedback needs and preferences of EFL graduate students to the three nominated themes defining supervisor written feedback to thesis writing in this study: content, genre, and linguistic feedback to thesis writing. Data was collected from 32 master's students from the TEFL and Media and Communications at Bahir Dar University, Ethiopia using a questionnaire and an unstructured interview. The participants' responses were tabulated and analyzed using descriptive statistics. The results indicated that both groups commonly preferred feedback on content the most. When sub-categories of this feedback were examined further, it was found that TEFL students favored gaps in theoretical understanding, but Media and Communications students preferred coverage and gaps in the literature. They also showed discrepancies regarding their preferences for part-genres in thesis writing and the various features of linguistic accuracy. The results of this study suggest that feedback on theses should be realized in regard to the needs and preferences of graduate students. Finally, implications for further research that could shed light on the resonant understanding of feedback on thesis writing are presented.
\end{abstract}

Keywords: thesis, feedback preference, content feedback, genre, linguistic feedback

\section{Introduction}

Written feedback on a student thesis is a critical aspect of supervision in higher education. However, it could also prove to be a stumbling block to the success of thesis/dissertation if supervisors do not consider their students' perceived needs and preferences for various forms of written feedback. Supervision in a postgraduate program is of paramount importance in higher education where supervising students on the research projects they conduct as a requirement for their graduation is one of the responsibilities of professors all over the world (Yinager, 2019). Feedback is interactive and involves continuous two-way communication that encourages teaching and learning among educators and students (Manjet, 2016). Indeed, the role of feedback in facilitating student learning has been advocated by many educational researchers (Aitchison, Catterall, Ross, \& Burgin, 2012; Evans, Hartshorn, McCollum, \& Wolfersberger, 2010; Pokorny \& Pickford, 2010; Stracke \& Kumar, 2010).

The mounting evidence on the role of feedback has also attracted considerable attention in higher education where effective and high quality feedback is found to be a key element of quality teaching in higher education (Ali, Watson, \& Dhingra, 2016; Basturkmen, East, \& Bitchener, 2014; Ghandi, \& Maghsoudi, 2014; Hoomanfard, Jafarigohar, Jalilifar, \& Hosseini, 2018; Leng, 2014; Wang \& Jiang, 2015). Another interesting recent development in the field of writing is that while the value of feedback in teaching and learning is consistently reiterated in educational literature, a considerable amount of research has also provided important assertions about the critical role of feedback in helping graduate students determine the parts of writing that are correct and the parts that need correction for improved writing as well as alerting students of their strengths and weaknesses in academic writing (Manjet, 2016). Thesis writing is a daunting experience for all graduate students who conduct research for the first time. Consequentially, this insight has significant pedagogical implications for supervisors of thesis writing, suggesting that instruction should be usually given either on written or oral feedback or both by supervisors when students are writing a thesis (Bitchener, Basturkmen, \& East, 2010). 
Given the multifarious functions of feedback on thesis writing discussed in the preceding paragraphs, the development of students' higher-order and critical thinking skills is an important one. Feedback helps in stimulating critical thinking among students to ensure the development of constructive ideas for writing (Manjet, 2016). As supervisors provide feedback, they teach their students a gradual release of responsibility that includes instilling higher-order transformative skills such as reflecting critically or interpreting meanings logically by assessing a thorough evaluation of their own work independently. In such a supportive environment, the students can begin to consider the real-life implications of the insights provided by their supervisors by inculcating them in their thinking. This will help them find solutions for the problems they encounter during the thesis writing process. Feedback is indispensable in teaching and learning and its role is documented in educational literature (Price, Handley, Millar \& O’Donovan, 2010; Yu \& Lee, 2013). In addition, Rowe and Wood (2008) posit that in order to achieve quality teaching and supervising, effective and quality feedback should be provided. Taken together, written feedback by the graduate students' supervisors and lecturers is a fundamental source of input for academic writing such as thesis writing (Bitchener et al., 2010).

At this juncture, it is essential to make clear distinctions between the two concepts related to supervisor feedback on thesis writing: effective and quality feedback on thesis writing. Quality and effective education has recently been an increasingly important concern in universities that policymakers, teachers, and other stakeholders are struggling to achieve. Although they seem to be similar, it is essential to make clear distinctions between the terms 'effective' and 'quality' as they are used in the context of this study. Education experts differ widely on meaning of the terms 'effective' and 'quality' feedback in regard to thesis writing in higher education, but this study defines 'quality' as any typical feedback used to attain the desired objectives of supervision on thesis writing. Similarly, the term 'effective feedback' refers to various means of supervision that are conducted with skills and strategies used for the ultimate goal of the supervision. Using the terms interchangeably, some researchers posit that in order to achieve quality teaching and supervising, effective and quality feedback should be provided (Rowe \& Wood, 2009).

One possible reason for the effectiveness of feedback can be ascribed to addressing the needs and preferences of students for supervisor feedback to thesis writing. It is also recognized that understanding students' perceived needs of feedback can be helpful for evaluating the appropriateness and relevance of current supervisory practices in thesis writing. A considerable amount of literature has discussed various types of feedback, such as direct and indirect feedback, peer and teacher feedback, oral and written feedback, and grammar and content feedback. Although a large body of research has explored these types of feedback, little is still known about graduate students' perceived needs regarding the three aspects of feedback in response to thesis writing: Content knowledge: its accuracy, completeness and relevance, Genre knowledge: the functions of different parts of a thesis, and Linguistic accuracy and appropriateness. Further, in spite of differences across various disciplines, the two major challenges that have hindered graduate students when writing their theses are a limited understanding of the characteristics of the thesis genre and its component parts (part-genres like the introduction and discussion sections/chapters) and uncertainty about the expectations and requirements of their discipline-specific communities of practice (Bitchner et.al., 2010).

Having established the appropriateness of the three themes defining supervisor written feedback for thesis writing nominated in this study, it is then important to understand the ways of delivering feedback on student thesis writing. Instruction should be usually given either in written or oral forms. This is because students will benefit twice when they receive both oral and written feedback. Oral feedback, such as teacher-student conferencing, is deemed necessary as it sheds some light on students' misunderstandings and difficulties while the supervisor discusses the written comments provided. The importance of written feedback is also acknowledged in thesis writing contexts since written feedback helps the student improve their academic writing. A study by Bitchener, Young, and Cameron (2005) found that combining written and oral feedback made for significant improvements in student writing over time, but it was oral feedback that had the added potential of allowing constructive comments that could meet the students' individual needs. Consequentially, a large body of research results also revealed that there is a growing trend that believes such blended forms of supervisory feedback should be given simultaneously. Supervisors almost always provide written feedback on their students' thesis drafts (Tee, Kumar, \& Abdullah, 2013), and the written feedback provided is usually supported with oral feedback through face-to-face meetings (Bitchener \& Basturkmen, 2006; Bitchener, Basturkmen, East, \& Meyer, 2011; Bitchener et al., 2005). 
A remarkable variant that has been emphasized in the literature regarding supervisor feedback in response to student thesis writing is students' preference variations towards the value of feedback to thesis writing. In connection with written feedback, for instance, various characteristics of feedback preferences have been reiterated in the literature (Bitchener et al., 2010). Previous research has also asserted that students value and appreciate written feedback on their grammar (Bitchner et al., 2011; Manjet, 2016). On the other hand, research has also reported various features of content or subject-area feedback as graduate students' most preferred feedback (Chokwe, 2015; Lee, 2008). Based on the interview results obtained from a similar English as a foreign language context, three factors (genre knowledge, content knowledge, and appropriation) were found to affect Iranian TEFL graduate students' perceived needs on the type of written feedback (Hoomanfard, Jafarigohar, Jalilifar, \& Hosseini, 2018).

Irrespective of these variations, one of the most notable assertions is that feedback for thesis writing can only be viewed as an important process if supervisors carefully consider the salient features of each feedback type in light of the literature when providing feedback. Concerning this, Hyland (2009) posits that the most helpful feedback is that which helps students understand the expectations of their disciplinary community. It "conveys implicit messages" about the values and beliefs of the discourse community, the nature of disciplinary knowledge, and student identities in the community (Hyland, p. 132). Bitchner et al. (2011) also suggested coherence and cohesion in argument creation as an example of graduate students' writing difficulties in thesis writing. Moreover, students valued feedback when they perceived that the feedback providers believed in their potential, cared about the improvement of their skills, and tried to be helpful (Can \& Walker, 2011).

\section{Literature Review}

\section{Theoretical Framework}

This study is informed by the premise of the socially mediated learning theory as it emphasizes the essence of social interaction and mediation. Vygotysky (1978) postulates that the potential for the cognitive development of a learner is limited to the Zone of Proximal Development (ZPD). According to Vygotysky (1978), this 'Zone' According to Vygotysky (1978), this 'Zone' is an important area that the student is cognitively prepared to examine things carefully with the help of a more experienced other to fully develop. Bitchener, et.al (2011) maintained that feedback helps students by enhancing the supervisor-supervisee relationship to help it take on a more egalitarian «peer-to-peer» relationship, with the former being the more capable peer whose role is to scaffold and negotiate the ZPD to ultimately develop as an independent thesis writer.

As the more experienced other, the supervisor can give provide scaffolding and other strategies to enhance learner curiosity until the learner develops complex skills. Further, the theory underscores the relevance of the holistic approach toward teaching (e.g. grammar should be taught not as a discrete element but it must be taught holistically to help the learner construct meaning). The fact that the theory underscores the importance of an integrated approach toward teaching helps the socially mediated learning theory of learning fit the purpose of this research, which is specific to thesis writing. Thus, supervisors should provide one form of feedback not just as a discrete element, but it must be provided holistically using various supervisor feedback mechanisms to thesis writing that help students elucidate their intellectual knowledge and research skills.

Taken together, this research was guided by the socially mediated learning theory as it underlines the essence of social interaction and mediation that aims to mediate how students think, suggesting that supervisory written feedback could act as remedial instruction to develop students' problem solving skill in thesis writing. This skill can be developed under the guidance of the supervisor, and hence the theory fits the purpose of this research as it sheds light on significance of a supervisor as someone who can support the learner with the development of complex skills through modeling, collaborative learning, and independent problem solving techniques to foster the intellectual knowledge and skills of learners through scaffolding and mediation.

\section{Supervisors' Written Feedback Types}

In the literature, various types of feedback are highlighted. For instance, on the basis of the amount of feedback provided for student writing, written corrective feedback can be comprehensive (unfocused), which refers to 
teacher's feedback in response to all of the errors committed by the student, a common time-consuming practice used by teachers (Lee, 2004, 2008), or selective (focused), where the teacher provides written feedback selectively on a number of linguistic features, such as sentence style, active/passive, verb tense, etc. Other forms include direct feedback, referring to the provision of the correct form or structure by the teacher (Ferris, 2003), or indirect feedback, referring to the indication of an error by the teacher through circling or underlining an error, indicating the number of errors in the margin, or placing a code such as SP for spelling or WW for wrong word (Ferris \& Roberts, 2001). However, as the purpose of this study is to explore the perceived written feedback needs of postgraduate students, this study focuses on three distinct feedback types provided by supervisors in response to student thesis writing; these are feedback on content, feedback on genre, and feedback on linguistic accuracy and appropriateness. A detailed account of these categories will be elaborated on in the methodology section.

Despite the fact that feedback constitutes a major form of instruction for higher-degree research students, the general focus of advisors has been reported as the struggle to articulate implicit knowledge (Paré, 2011). Microlevels errors include ambiguity in references, the misuse or over use of conjunctions and repetition, the misuse of lexical items, etc., and written feedback on a 'micro-level' refers to the types of feedback given to treat learner errors with regard to learners' use of grammatical accuracy and appropriate word order patterns, as well as acceptable grammatical systems and forms (e.g., tense, agreement, pluralization), patterns, and rules (Brown, 2007). With regard to this, having analyzed the considerable discrepancies in the techniques of teacher error correction in his stud. Similarly, Leng (2014) conducted a study analyzing the written feedback on ESL students' written assignments to shed light on how feedback acts as a type of written speech between the lecturer and student. The results from the study indicated that the written feedback provided to students was helpful and useful in their essay revision. The study concludes that the feedback was effective for the students because they were able to attend to the revision of their second draft well.

\section{Graduate Students' Written Feedback Preferences}

The growing amount of research on supervision practices has revealed graduate students' written feedback preferences for supervisor written feedback in response to thesis writing. One of the other functions of feedback that has been proposed in the literature is part-genre, which is feedback offered to comment on students' theses regarding the different purposes, structures and organization, and parts of a thesis (Bitchner, et al., 2010). Manjet (2016) indicated that graduate students preferred the content of their academic work to be emphasized in the feedback and not merely focus on language and formatting issues.

In a similar vein, Hooman Saeli (2019) employed semi-structured interviews to obtain data from 14 teachers and 15 students to investigate teachers' practices and students' preferences regarding grammar-centered written corrective feedback (WCF) in an Iranian EFL context. The study revealed that the teachers' practices were driven by the students' preferences in that they mostly provided teacher-generated grammar feedback simply because they believed that their students preferred this type of correction. Esra (2020) also examined mentoring practices and mentor growth areas as perceived by three student-teachers in a 12-week practicum period in a Turkish English Language Teaching (ELT) context using interviews and reported that mentors rarely employed practices related to feedback, pedagogical knowledge, and system requirements.

Regarding postgraduate students' preferences about supervisors' written feedback, Hoomanfard, et al. (2018) used a mixed-method design to examine Ph.D. and MA students' needs for supervisor written feedback on their theses/dissertations. The results indicated that there were similarities (argument, logical order, transition, clarity, and references decisions) and differences (inclusion of information, formatting, grammar, conclusion, introduction, and consistency) between the priorities given by MA and Ph.D. students. With a particular emphasis on MA students, the results showed that the MA students' expressed priorities that were not similar to those of the supervisors except in three areas (argument, formatting, and grammar). The survey study of Can and Walker (2014) also revealed the Ph.D. students' feedback needs in order of priorities as arguments, the conclusion, clarity and understandability of the statements, inclusion or exclusion of information, the introduction, consistency in the overall paper, logical order of ideas, transition, paragraphs or sections, grammar, formatting, and references. The study further reported that Ph.D. students' ratings were lower for more mechanical aspects such as grammar, formatting, and referencing. 
Zhan (2016) also investigated a teacher's and her students' preferences regarding written teacher feedback in a college English as a foreign language (EFL) writing class in China. The study used essays, questionnaires for 62 students, and interviews from the teacher and her six students to identify the types of feedback given by the teacher, the perceptions and preferences of the students, and the perceptions of the teacher. The findings of the study indicated that while the teacher's written feedback covered content, organization, vocabulary, grammar, and mechanics, the students reported that they benefited from and preferred feedback on organization the most, which was not expected by their teachers. Consequently, the study suggested that foreign language writing teachers communicate more with their students about their feedback practices, and be aware of students' perceptions and preferences so that their writing instruction could be more effective.

\section{Significance of the Study}

This study is based on the notion that understanding a great deal about student perceived needs and preferences is helpful because of the potential of this factor to boost the quality of written feedback in thesis writing. The results of the present study can hopefully familiarize EFL supervisors with the importance of considering the needs of their students during the thesis writing process. The findings of the study could also lay the foundations for new graduate school guidelines that could inform graduate supervisors about potential misunderstandings between supervisors and students, and help them understand how to make supervision in thesis writing effective.

This may also help to design better supportive mechanisms for supervisors in terms of scaffolding their students, which would ultimately produce more effective supervisory practices. Unlike other similar EFL studies that were conducted to investigate feedback preferences in classrooms (Amrhein \& Nassaji, 2010; Ghandi \& Maghsoudi, 2014), the present study examined the feedback needs of graduate students to thesis writing, which is an under-researched topic in a totally untouched context of supervision in universities in Ethiopia. All things considered, the results of this study could be significant in informing supervisors to critically analyze their students' writing preferences and adjusting how to balance these preferences in written feedback, thereby helping their students become more successful at thesis writing. It may also be used to provide insights into understanding the perceived needs of Ethiopian graduate students compared with the perceived preferences of graduate students in other EFL contexts.

\section{Rationale for the Study}

Two major interrelated points could primarily justify the need for further studies on feedback preferences. In Ethiopian universities, students who pursue master's degrees are required to write a thesis under the supervision of one or two advisors as a partial fulfillment for their master's degree program. Thus, it can be a challenge for these students without the support of the supervisors assigned to them. Moreover, despite the fact that research courses that serve as a vehicle to build students' research skills are offered in both undergraduate and graduate schools, student researchers have little or no capacity and understanding of the basic research components and skills necessary to undertake a study (Yenus, 2018). Local research has also indicated that many graduate students had no adequate writing skill when they started writing their theses (Zeleke, 2017).

The findings of numerous studies (Aitchison et al., 2012; Cotterall, 2011; Paré et al, 2011; Wang \& Li, 2011) have showed considerable interest in postgraduate research writing, as little or no research has been conducted to specifically examine the perceptions of what graduate students think are the most important aspects of supervisor written feedback on thesis writing. In a similar vein, several studies have focused on teachers' written feedback to respond to their students' writing in the classroom rather than on student thesis writing (Katayama, 2007; Wang, 2010), indicating a dearth of research into writing practices at the postgraduate level. Therefore, this study was designed to respond to this need. In light of all this, the following research questions were formulated.

1. What are the perceived preferences of graduate students for their supervisors' written feedback?

2. Is there a significant difference in the mean preference scores between TEFL and Media and Communication Students? 


\section{YENUS NURIE}

\section{Methodology}

\section{Research Design}

This study adopted a multi-method approach so as to triangulate the data obtained from the students' survey questionnaire and the interview responses. The students' views regarding the needs and preferences of supervisory feedback were elicited initially from the responses of the survey questionnaire adapted from the exploratory, descriptive study of Bitchner et al. (2010) that investigated what supervisors said they focused on when giving feedback, which was followed by more in-depth questioning about the responses through the use of semistructured interviews. Having established the data collection instruments used for this study, it is then important to understand the major feedback areas used to analyze the students' written feedback preferences.

The first theme that was derived regarding the types of supervisory written feedback to student thesis writing was feedback on content, which refers to comments on gaps in the literature, gaps in theoretical understanding and coverage, the potential irrelevance of the thesis, the wider significance of the work, and gaps in the justification or explanation of arguments. Part-genre feedback includes the structure of what goes where and examples of what is expected, purpose of part-genre, part-genre skills required for each genre and expected word count from a thesis constitutes the second major theme of the study. The third theme was a written feedback that contains punctuation, spelling and capitalization, systematic errors, writing style, how to develop ideas with supportive and counter evidence, writing coherence and cohesion, the quality of writing, grammar (verb tenses, subject/verb agreement, article use...etc.), and the appropriateness of vocabulary choice and academic register was also developed to help understand written feedback regarding the students' preferences for linguistic accuracy and appropriateness (Bitchener, et al., 2010).

\section{Population and Participants}

The target population of this study was graduate students who were pursuing a master's degree in various colleges at Bahir Dar University. The participants in the study were 20 English and 12 Media students who were currently enrolled at Bahir Dar University to earn their master's degree in Teaching English as a Foreign Language and Media and Communications respectively. Among the participants who were registered for the two disciplines, $68.8 \%$ were males and $31.2 \%$ were females. A total of 32 students participated in filling out the survey questionnaire in the faculty of humanities, where purposive sampling was used. Specifically, 14 (70\%) of the participants in TEFL were males, and six (30\%) were females, whereas eight (66.7\%) of the participants in Media and Communication were males and four (33.3\%) were females.

\section{Research Procedures}

The students were informed about the purpose of the questionnaire before they began filling out the form. Then, the researcher explained the instructions of the questionnaire that required them to rate each item based on their preferences regarding the various features of written feedback on thesis writing on a Likert scale ranging from "strongly agree" (5) to "strongly disagree (1)." After the participants were informed about the purpose of the questionnaire, the researcher distributed the questionnaire to the participants and asked that they be completed in 30 minutes. Finally, the researcher collected the questionnaires in person after making sure that the students completely filled them out. The results of the survey questionnaire were then used to analyze the participants' perceptual preferences for written feedback on thesis writing.

\section{Data Collection Instruments}

Data were obtained from a standardized questionnaire that was adapted by the researcher from Bitchner et al., 2010). The questionnaire consists of 17 items questions that were developed from an extensive literature review of published studies on various features of supervisory feedback for thesis writing. The Cronbach Alpha reliability of the needs for written feedback section of the questionnaire was .79. To ensure the consistency of the standard questionnaire in the context of the present study, a pilot study was carried out to test and improve the questionnaire used for this study. It was also reviewed by three experienced researchers to determine the content and face validity of the questionnaire. The researcher used the feedback to improve the questionnaire by removing unnecessary or repetitive statements. The survey instrument used for this study was also tested for reliability. The questionnaire was administered and pilot tested by other groups of students who were not part of the main study. 
The pilot study helped the researcher revise unclear questions and make necessary changes for the administration of the questionnaire items before they were launched in the main study.

This standardized questionnaire was also field tested in the study of Yenus (2018) that examined 55 doctoral students' perceptions and preferences about supervisor written feedback to respond to student dissertations at Bahir Dar University, Ethiopia. In the study, to check the internal consistency of the reliability of the items, Cronbach's alpha coefficient was computed through SPSS version 20 and found to be 0.80 . Meanwhile, since the level of the participants was still different from the study of Yenus (2018), the present questionnaire was again pilot tested and underwent a subsequent reliability test, which was found to be 0.82 Cronbach's alpha. The second instrument was an unstructured interview. Five TEFL students and three Media and Communications students were selected randomly for the interview. The purpose of the interview was to provide additional insights into the questionnaire results of this study and investigate their perceived needs and preferences regarding supervisor written feedback. The interviews were conducted after the responses obtained from students' questionnaire had been analyzed. The students' interview responses were recorded, categorized, and thematically analyzed.

\section{Data Analysis}

This study aimed to understand graduate students' feedback preferences for written feedback. Thus, the descriptive statistics results of the questionnaire were used to analyze the general feedback preferences of graduate students. An independent samples t-test was used to examine whether there was a significant difference between TEFL and Media and Communication graduate students regarding their feedback preferences. To conduct the independent samples t-test, the grand mean scores of both groups were compared to evaluate whether there was a statistically significant difference in their perceptions regarding written feedback. To be specific, the survey questionnaire aimed at examining feedback preferences of university students who enrolled in two disciplines regarding the various features of thesis writing as the content, part-genre, and linguistic accuracy and appropriateness. The students' responses obtained from the survey questionnaire were collected and imported into SPSS and calculated. The participants' responses to each item on the questionnaire were then summarized, tabulated, and analyzed using descriptive statistics such as mean and standard deviation and inferential statistics from an independent samples t-test. The interview data obtained from both the TEFL and Media and Communication students' explanatory responses was transcribed, coded, categorized into themes, and analyzed qualitatively.

\section{Results}

The results obtained from the questionnaire and interview data were organized according to the order in which the two research questions were structured: (1) the types of written feedback graduate students emphasized and (2) the comparison results of feedback preferences between TEFL and Media and Communication students.

\section{The Students' Perceived Needs and Preferences for Various Types of Written Feedback}

Table 1

Descriptive Statistics for Graduate Students' Preferences for the Specific Features of Content Feedback

\begin{tabular}{|c|c|c|c|c|c|c|c|c|}
\hline No. & Content Feedback & Group & Mean & SD & MD & $\mathbf{F}$ & $\mathbf{t}$ & p-value \\
\hline \multirow[t]{2}{*}{1.} & Gaps in theoretical understanding and coverage & TEFL & 4.45 & .671 & & & & \\
\hline & & Media & 3.50 & .527 & .955 & .322 & 5.185 & .000 \\
\hline \multirow[t]{2}{*}{2.} & Gaps in the literature & TEFL & 3.55 & 1.011 & & & & \\
\hline & & Media & 4.30 & .949 & -.755 & .445 & -1.721 & .055 \\
\hline \multirow[t]{2}{*}{3.} & Irrelevance of thesis & TEFL & 2.64 & 1.177 & & & & \\
\hline & & Media & 3.10 & 1.101 & .464 & 1.429 & -1.214 & .301 \\
\hline \multirow[t]{2}{*}{4.} & Wider significance of the work & TEFL & 2.18 & 1.435 & & & & \\
\hline & & Media & 3.80 & 1.135 & -1.618 & 1.778 & -3.452 & .004 \\
\hline \multirow[t]{2}{*}{5.} & Gaps in the justification or explanation of arguments & TEFL & 3.09 & 1.109 & & & & \\
\hline & & Media & 3.40 & 1.174 & -.309 & .018 & .794 & .478 \\
\hline
\end{tabular}

*SD: Standard Deviation *MD: Mean Difference 


\section{YENUS NURIE}

Table 1 displays the means, standard deviation, mean difference, and p-value results of graduate students' preferences for the specific features of content feedback on thesis writing. With a mean of 4.45 and standard deviation of .671, commenting on gaps in theoretical understanding and coverage was the most preferred type of supervisor feedback for the TEFL participants, whereas the most popular form of feedback for Media and Communications students (with a mean of 4.30 and standard deviation of .949) was Gaps in the literature. While both groups agreed that feedback on content was the most important feedback for their thesis writing, there is a glaring discrepancy between TEFL and Media and Communications students' views regarding some of the sub-categories for content feedback.

Based on the independent samples t-test results, we can conclude that TEFL participants showed significant differences on their perceptions regarding two items out of the five sub-categories of feedback on content. "Gaps in theoretical understanding and coverage" had a mean difference of .955 was significant at 0.000 for TEFL participants, whereas "Wider significance the work" had a mean difference of -1.618 with a significance level of $\mathrm{p}<0.05$. for Media and Communication participants. However, no statistically significant difference was found among the participants by discipline regarding their perceived needs toward the remaining three sub-categories.

The interview results of TEFL students' priorities were close to those expressed by Media and Communication students in comments related to content or subject areas. The thematic analysis of the students' interviews indicated that all of the students prioritized feedback on content. Both groups particularly acknowledged the indispensable necessity of comments on gaps in the literature and theoretical understanding. The interviews were particularly enlightening in regard to the types of gaps that both groups of students shared as the most important feedback. A TEFL student stated:

As a graduate student, I must have a clear understanding of the topic and the related literature and the conceptual and theoretical framework so that my research would be scientific. Thus, I expect my advisor to read my thesis thoroughly and comment on how the writing pieces are linked with the review of the related literature as I am not familiar with how to accurately review an article or books.

The verbal account of the following interviewee result from Media and Communications signifies his strong preference for feedback on content.

I would prefer my supervisor to comment on the accuracy, completeness, and relevance of content written in my thesis. As to me, commenting on content is the most important feedback. I am unaware of the difference between conceptual and theoretical frameworks, and it is usually difficult for me how to review the literature and how to relate my thesis to the review of related literature.

Table 2

Descriptive Statistics for Graduate Students' Preferences for the Specific Features of Part-Genre

\begin{tabular}{|c|c|c|c|c|c|c|c|c|}
\hline No. & Genre Feedback & Group & Mean & SD & MD & $\mathbf{F}$ & $\mathbf{t}$ & p-value \\
\hline \multirow[t]{2}{*}{1.} & Content specific to the various part-genres of the thesis & TEFL & 3.64 & 1.217 & & & & \\
\hline & & Media & 3.50 & 1.650 & .136 & 2.349 & .847 & .795 \\
\hline \multirow[t]{2}{*}{2.} & Structure of what goes where and examples of what is expected & TEFL & 3.23 & 1.110 & & & & \\
\hline & & Media & 3.30 & 1.160 & -.073 & .027 & .326 & .867 \\
\hline \multirow[t]{2}{*}{3.} & Purpose of part-genre & TEFL & 2.45 & 1.299 & & & & \\
\hline & & Media & 4.20 & .789 & -1.745 & 4.293 & -3.248 & .000 \\
\hline \multirow[t]{2}{*}{4.} & Expected word count from a thesis & TEFL & 2.64 & 1.560 & & & & \\
\hline & & Media & 2.70 & 1.567 & -.267 & .882 & -.030 & .916 \\
\hline \multirow[t]{2}{*}{5.} & Gaps in the justification or explanation of arguments & TEFL & 3.09 & 1.109 & & & & \\
\hline & & Media & 3.40 & 1.174 & -.309 & .018 & .794 & .478 \\
\hline
\end{tabular}

*SD: Standard Deviation *MD: Mean Difference

Table 2 displays the means, standard deviation, mean difference, and p-value results of graduate students' preferences for the specific features of part-genre feedback on thesis writing. With respect to the specific 
components of feedback on part-genres, TEFL respondents agreed with a mean of (3.64) and standard deviation of 1.217 that content specific to the various part-genres of the thesis was the most useful component of the part-genres on thesis writing. With a mean of (4.20) and standard deviation of .789, the most preferred partgenre-related feedback for Media and Communications students was supervisor comments regarding the purpose of part-genre. Based on the data, both groups of participants were overwhelmingly positive about the role of all of the sub-categories of feedback on part-genre except for one item. The students' responses from the two disciplines on part-genre revealed some significant discrepancies in their concerns regarding the importance of various structures and components of the thesis. Students in Media and Communication differed significantly in their perception regarding the importance of the part-genre sub-category "Purpose of partgenre" with a mean difference of -1.745 and a significance level of $p<0.05$.

The interview responses also revealed consistent results with the questionnaire data regarding the students' shared values for the sub-category of feedback on genre-content specific to the various part-genres of the thesis. Both TEFL and Media and Communications students stressed the value of comments on content specific to the various part-genres of the thesis. The following two samples were taken from the students who participated in the interview. A student from TEFL noted:

Generally, as I am not an experienced researcher, I think that I have inadequate research skills necessary for thesis writing. That is why I chose feedback on content specific to the various part-genres of the thesis. I am not sure if I am writing research to an acceptable standard. I hope my advisor's feedback on this may help me decipher the quality of academic writing in research.

Likewise, another student from Media and Communications expressed:

I have trouble in academic writing. Particularly, I have a lot of problems structuring and organizing my thesis. I don't have any idea of what to write in various components of a thesis. Therefore, it is important for me to receive such comments on my thesis.

Table 3

Descriptive Statistics for Graduate Students' Preferences for the Specific Features of Linguistic Feedback

\begin{tabular}{|c|c|c|c|c|c|c|c|c|}
\hline No. & Linguistic Feedback & Group & Mean & SD & MD & $\mathbf{F}$ & $\mathbf{t}$ & p-value \\
\hline \multirow[t]{2}{*}{1.} & Punctuation, spelling, and capitalization & TEFL & 2.00 & 1.113 & & & & \\
\hline & & Media & 2.90 & 1.449 & -.900 & .028 & -2.240 & .063 \\
\hline \multirow[t]{2}{*}{2.} & Systematic errors & TEFL & 2.18 & 1.402 & & & & \\
\hline & & Media & 3.60 & 1.174 & -1.418 & 1.773 & -3.106 & .009 \\
\hline \multirow[t]{2}{*}{3.} & Writing style & TEFL & 2.50 & 1.225 & & & & \\
\hline & & Media & 3.80 & 1.229 & -1.300 & .734 & -3.149 & .009 \\
\hline \multirow[t]{2}{*}{4.} & How to develop ideas with supportive and counter evidence & TEFL & 1.95 & .999 & & & & \\
\hline & & Media & 3.70 & 1.160 & -1.745 & .144 & -4.526 & .000 \\
\hline \multirow[t]{2}{*}{5.} & Writing coherence and cohesion and quality of writing & TEFL & 3.23 & 1.378 & & & & \\
\hline & & Media & 3.90 & .876 & -.673 & 4.683 & -1.388 & .168 \\
\hline \multirow[t]{2}{*}{6.} & Grammar (tenses, subject/verb agreement, article use, etc.) & TEFL & 2.09 & 1.151 & & & & \\
\hline & & Media & 2.80 & 1.135 & -.709 & .468 & -2.104 & .115 \\
\hline \multirow[t]{2}{*}{7.} & Appropriateness of vocabulary choice and register & TEFL & 3.05 & 1.174 & & & & \\
\hline & & Media & 4.60 & .516 & -1.555 & 4.422 & -3.704 & .000 \\
\hline
\end{tabular}

*SD: Standard Deviation *MD: Mean Difference

Table 3 displays the means, standard deviation, mean difference, and the p-value results of graduate students' preferences for the specific features of linguistic feedback on thesis writing. The data showed that graduate students from TEFL gave little value to all linguistic aspects of feedback except for Writing coherence and cohesion and quality of writing with a mean of 3.23 and standard deviation of 1.378. Media and Communications students favored Appropriateness of vocabulary choice and register with a mean score 4.60 and standard deviation of .516. The students from TEFL also expressed feedback on Appropriateness of vocabulary choice and register with a mean of 3.05 and standard deviation of 1.174 as their second priority. Writing coherence 
and cohesion and quality of writing received a mean of 3.90 and standard deviation of .876 from Media and Communications students. Seven specific feedback types were listed under feedback on the linguistic accuracy section. The two groups didn't show any statistical difference on three of the questionnaire items.

On the other hand, there were statistically significant differences between the adjusted mean scores of the remaining four items with regard to the sub-categories of linguistic accuracy and appropriateness at significant levels. This implies that students' responses differed according to their discipline in these four examples of linguistic feedback: 'Systematic errors', 'writing style', 'how to develop ideas with supportive and counter evidence', and 'appropriateness of vocabulary choice and register' with a mean difference of $-1.418,-1.300$, -1.745 , and -1.555 respectively at $p<0.05$. Surprisingly all four of these sub-categories of linguistic feedback was attributed to Media and Communication students.

The interview results of the TEFL graduate students replicated the students' lower preferences for linguistic accuracy. The low level of priority given for this type of feedback might have stemmed from the students' prior experiences as all of the interviewees were experienced EFL secondary school English teachers for many years as one of the student noted:

I don't see the relevance of receiving feedback on linguistic accuracy and appropriateness at this level because I don't think that comments on structural use of the language help me achieve the big picture of thesis writing. I also don't think that it adds something to my thesis writing.

Another TEFL student stated:

As an English teacher, I have studied English in a university. I have also been teaching English for several years, and hence I believe that I gained adequate knowledge on the correct use of the English language. Therefore, I don't see the point of receiving grammar and language use feedback as this is not so difficult to manage for graduate students like me.

Conversely, feedback on linguistic accuracy was a big concern that mattered most for Media and Communications students. Apart from commenting on punctuation, spelling, capitalization, and grammar in their thesis writing, the participants from Media and Communications expressed that they needed the other sub-categories of linguistic accuracy, acknowledging that they had trouble producing a coherent and quality academic thesis as illustrated by one respondent:

I want my advisor to comment on how to develop ideas, present arguments, and produce effective scientific writing. As the purpose of writing research is to communicate with the scientific community through my thesis, I think that my thesis should be well organized and structured, which is difficult to achieve without the proper linguistic feedback.

\section{Results of Feedback Preferences between TEFL and Media and Communication Students}

Table 4

Independent Sample t-test Results for Graduate Students' Preferences for General Written Feedback

\begin{tabular}{llllllllll}
\hline No. & Feedback Category & Group & No & Mean & SD & MD & F & t & p-value \\
\hline 1. & Content & & TEFL & 20 & 3.18 & .614. & & & \\
& & Media & 12 & 3.62 & .676 & -.438 & .016 & -1.583 & .080 \\
\hline 2. & Part-Genre & TEFL & 20 & 2.99 & .811 & & & & \\
& & Media & 12 & 3.43 & .541 & -.446 & .268 & -.894 & .113 \\
\hline $3 . \quad$ Linguistic & TEFL & 20 & 2.43 & .784 & & & \\
& & Media & 12 & 3.61 & .547 & -1.186 & 2.413 & 5.189 & .000 \\
\hline & Total & TEFL & 20 & 2.87 & 1.017 & & & & \\
& & Media & 12 & 3.55 & .967 & .68 & .098 & -3.888 & .002 \\
\hline
\end{tabular}

Notes: $\mathrm{N}=32 * \mathrm{p}<.05$ (significant at less than .05 level) 
Table 4 displays a summary of the independent samples t-test results for graduate students' preferences for the general written feedback on thesis writing. Regarding general feedback preferences, the overall responses obtained from the two groups showed that both groups were similarly concerned with feedback on content the most. This value underscores the point that students really appreciated the importance of content or subjectarea feedback. Specifically, TEFL students placed great importance on comments regarding the content and subject area with a mean average value of 3.18 and standard deviation .614, whereas Media and Communications students showed their preferences for comments related to content in their thesis writing with a mean average value of 3.62 and standard deviation .676. Recalling from Table 3, it was evident that the quantitative data revealed statistically significant differences among the two groups of students' perceptions toward various sub-categories of linguistic feedback, which resulted in an overall statistical difference between them regarding the linguistic feedback and appropriateness.

Overall, Media and Communications students gave high ratings for feedback on content and linguistic features of supervisor comments, which indicates that the students would like their advisors to provide these comments in detail. From the researcher's shared experience, the researcher had hypothesized that students from both groups would prefer feedback on linguistic accuracy most. In contrast, with the mean difference of 1.186, participants from TEFL tended to have little or no interest in feedback on the linguistic aspects of their thesis work, indicating that TEFL students did not want or expect their advisors to comment on this.

The independent samples t-test was used to compare the two groups' scores on the same variable feedback and its sub-categories. The mean scores of TEFL and Media and Communication students were compared to evaluate whether there was a difference in their perception regarding written feedback. Inferring from the data, although both groups were similarly concerned with feedback on content the most, it was also evident that with a mean difference of .68, a statistically significant difference was observed between the two groups with regard to their overall perceived needs of feedback at $p<0.005$. This result, could be ascribed to the linguistic accuracy and appropriateness in favor of Media and Communication students.

Table 5

Descriptive Statistics of Each Aspect of the Students' Perceived Needs of Feedback Instrument

\begin{tabular}{lccccccc}
\hline & Mean & SD & Skewedness & Kurtosis & Min & Max & N \\
\hline Feedback on Content & 3.32 & .656 & -.585 & 1.298 & 1 & 5 & 32 \\
Feedback on Part-genre & 3.13 & .757 & -730 & .749 & 1 & 5 & 32 \\
Linguistic Feedback & 2.80 & .903 & -.050 & -.081 & 1 & 5 & 32 \\
\hline
\end{tabular}

"SD: Standard Deviation *Min: Minimum *Max: Maximum *N: Total number

As indicated in the table above, in all four of the feedback needs, the minimum and maximum values were one and five, respectively. The variables' normal distribution of the data was supported by the results. Since both the degrees of skewedness and kurtosis were less than the absolute value of one, the variables were normally distributed.

Table 6

The Questionnaire Items and Final Three-Factor Structure of Students' Perceived Needs

\begin{tabular}{|c|c|c|c|c|}
\hline & & \multicolumn{3}{|c|}{ Factor } \\
\hline & & 1 & 2 & 3 \\
\hline \multicolumn{5}{|c|}{ Factor 1: Feedback on Content needs } \\
\hline 1. & Gaps in theoretical understanding and coverage & .820 & & \\
\hline 2. & Gaps in the literature & .785 & & \\
\hline 3. & Irrelevance of the thesis & .729 & & \\
\hline 4. & Wider significance of the work & .652 & & \\
\hline 5. & Gaps in the justification or explanation of arguments & .740 & & \\
\hline \multicolumn{5}{|c|}{ Factor 2: Feedback on Part-genre needs } \\
\hline & Content specific to the various part-genres of the thesis & \multicolumn{3}{|c|}{.754} \\
\hline & Structure of what goes where and examples of what is expected & \multicolumn{3}{|c|}{680} \\
\hline
\end{tabular}




\begin{tabular}{|c|c|c|c|c|}
\hline & & \multicolumn{3}{|c|}{ Factor } \\
\hline & & 1 & 2 & 3 \\
\hline 8. & Purpose of part-genre & \multicolumn{3}{|c|}{.842} \\
\hline 9. & Expected word count for a thesis & \multicolumn{3}{|c|}{.714} \\
\hline \multicolumn{5}{|c|}{ Factor 3: Linguistic Feedback needs } \\
\hline 10. & Punctuation, spelling, and capitalization & & & 772 \\
\hline 11. & Systematic errors & & & .626 \\
\hline 12. & Writing style & & & .761 \\
\hline 13. & How to develop ideas with supportive and counter evidence & & & .758 \\
\hline 14. & Writing coherence and cohesion and quality of writing & & & .663 \\
\hline 15. & Grammar (Tenses, subject/verb agreement, article use, etc.) & & & .687 \\
\hline 16. & Appropriateness of vocabulary choice and register & & & .793 \\
\hline
\end{tabular}

Table 7

Cronbach's Alpha for Each Aspect of the Students' Questionnaire

\begin{tabular}{lcc}
\hline & Cronbach's Alpha & Number of items \\
\hline Feedback on Content needs & .782 & 5 \\
Feedback on Part-genre needs & .790 & 4 \\
Linguistic Feedback needs & .769 & 7 \\
Total & .776 & 16 \\
\hline
\end{tabular}

\section{Discussion}

A growing body of research is investigating students' preferences for supervisor written feedback for thesis writing as examining student needs and preferences may help researchers and pedagogic experts fully understand the benefits of various types of supervisor written feedback to improve student thesis writing. This study sought to examine how EFL graduate students perceive the three major written feedback types provided by supervisors for thesis writing. Although a small-sized survey, overall, the results of this study demonstrate that the students held a very positive view towards the three major feedback types on thesis writing and preferred feedback on content the most. This conceptualization, as well as the more positive tendency towards written feedback reported in this study, can be considered vital, and signals the importance of considering the needs of students when providing supervision on thesis writing, since it might be a good idea for teachers to offer more feedback on the content and structure of their students' work for advanced EFL learners (Chen, Nassaji, \& Liu, 2016).

The results also revealed that both TEFL and Media and Communication students really appreciated the importance of content or subject-area feedback. It was also indicated that both groups of students still expressed a favorable preference for part-genre feedback on their thesis writing. This is a reminiscent of Manjet's (2016) conviction that graduate students preferred feedback to be on the content of their academic work and not merely focus on language and formatting issues. Given that student researchers have little or no capacity and understanding of basic research components and the skills necessary to undertake a study (Yenus, 2018), the results of this study that showed students' highest preference for feedback on content that includes key research skills such as gaps in the literature, gaps in theoretical understanding and coverage, irrelevance of the thesis, wider significance the work, gaps in the justification or explanation of arguments is not surprising. Similar EFL student perceptions towards content feedback were reported in the study by Bitchener et al. (2011), in which the students who participated in the study thought content feedback was the most useful for their thesis writing. In other similar studies, it was reported that although teachers' practices were driven by the students' preferences, these teachers mostly provided teacher-generated grammar feedback simply because they believed that their students preferred this type of correction (Hooman Saeli, 2019).

The present study also aimed to understand whether the students' perceptions significantly differed across the two disciplines: TEFL and Media and Communications. The results of this study revealed that there were more 
similarities than variations among the two groups of students' feedback preferences. The second sub-theme was along the lines of the specific components of each piece of written feedback. It was found that gaps in theoretical understanding and coverage and gaps in the literature was the most popular form of feedback for both groups. However, when the students' needs and preferences for the sub-categories of content feedback were further examined, the students showed significant differences. The sub-category "gaps in theoretical understanding and coverage" could be ascribed to TEFL participants, and "wider significance the work" could be ascribed to Media and Communication participants. While the graduate students' perceived needs might have been affected by their prior experiences in the form of academic writing experience, journal feedback, and exposure to a similar genre (Hoomanfard, et. al., 2018), taking this variation into account can be seen as an important reminder for supervisors since evaluating feedback quality needs careful consideration on the extent to which staff and students agree on the purpose of the feedback (Price et al., 2010).

Another interesting result was the students' wide range of preferences for feedback on part-genre, although both groups of respondents alluded to their difficulties writing and organizing their theses. These discrepancies might be because the academic writing practices the two groups of students brought from their prior academic learning backgrounds might have affected their expectations in their current thesis writing (Manjet, 2015), indicating the necessity for considering the particular culture of academic writing trends in each discipline when providing feedback on student thesis writing. The students' responses about their gaps in content specific to the various part-genres of their theses were particularly enlightening as supervisors are expected to guide the student researchers throughout their study and provide the time, expertise, and support to foster the candidate's research skills and attitude as well as to ensure the production of research of an acceptable standard (Heath, 2002).

A substantial amount of research on students' preferences for supervisor written feedback for thesis writing has been documented. The students' lowest preferences for linguistic accuracy reported in this study were in contrast to previous research which asserted that students valued and appreciated written feedback about grammar (Bitchner et al., 2011; Manjet, 2016). Particularly, the students' real concern on the two items pertinent to organization in academic writing: appropriateness of vocabulary choice and register, and writing coherence and cohesion and quality of writing could provide corroborative evidence for the results of previous research in that graduate students face challenges in their academic writing practices in the context of expressing ideas, linking ideas, sequencing their assignment, and ensuring clarity in their writing (Manjet, 2016). Although why these students reported the lowest priority for receiving comments pertinent to feedback on linguistic accuracy requires further study, it can be assumed that their prior knowledge might have affected their preferences as students' linguistic ability and linguistic self-confidence could affect the their perceptions regarding the need for feedback on their thesis/dissertation (Hoomanfard, et. al., 2018).

The convergent preference between TEFL and Media and Communications students in this study where students in both disciplines acknowledged that they needed more comments on content areas was very strong. However, the researcher took a very cautious approach to this finding as this realization may be due to the influence of the constant use of the same correction methods that lead students to think they are the best methods (Lee, 2004). On the other hand, this result was consistent with the results of the study of Yenus (2018) that compared the focus of feedback between TEFL and Media and Communications supervisors by analyzing the samples of supervisors' written feedback in the final version of student theses. Concurrently, the views of the respondents of the present study were, therefore, in tandem with his assertion that supervisors in both disciplines focused feedback on content the most, implying the congruence between graduate students' feedback preferences and supervisors' practices in responding to student thesis writing. Therefore, the results of this study that showed that various features of content or subject-area feedback as graduate students' most preferred feedback is also in line with previous research (Bitchner et al., 2011; Chokwe, 2015; Lee, 2008; Manjet, 2016).

\section{Conclusion}

The quantitative analysis of the questionnaire results and the interview responses of the participants revealed the following conclusions. They showed that feedback on content was the graduate students' most preferred feedback, indicating that this type of feedback was the most important type of feedback that the participants 


\section{YENUS NURIE}

were concerned with. The results of this study also showed that both groups of students seemed to equate the importance of the provision of feedback on content. Concerning the second research question, congruence and discrepancies between students from TEFL and Media and Communication students emerged. While the students from both groups valued feedback on content the most, the students' preferences were also incongruent with supervisor feedback, which could be ascribed to linguistic accuracy and appropriateness in favor of Media and Communication students. Further, the participants also showed discrepancies regarding their preferences for part-genres on thesis writing and on the various features of linguistic accuracy. The study also showed that students across the two disciplines differed in their feedback preferences regarding the specific components of each category in thesis writing.

Based on the major findings, it is suggested that efforts be made for the better realization of students' need and preferences in thesis writing. Advisors also need to approach their supervision more thoughtfully by linking theory and practice with regard to feedback for thesis writing. All things considered, instructors should critically analyze their students' writing preferences and adjust how to balance these preferences for written feedback thereby helping their students with successful thesis writing.

It is hoped that this research provides a significant contribution to scientific knowledge pertaining to supervision in the higher education context. The participants in this study that came from two disciplines, namely TEFL and Media and Communications were found to be divided in their opinions towards some aspects of feedback for thesis writing. Therefore, the reasons behind their preferences were not examined as this was not the purpose of this study, indicating the need for future studies that examine this issue including other data gathering tools, such as focus-group discussions and text analysis of student theses. Another limitation was that the sample size in the TEFL group was more largely represented than the students who participated from Media and Communications; hence this may have implications for future research examining students' preferences with a fairer representation of students from the two disciplines.

\section{References}

Aitchison, C., Catterall, J, Ross, P., \& Burgin, S. (2012) 'Tough love and tears': Learning doctoral writing in the sciences, Higher Education Research \& Development, 31(4), 435-447. http://dx.doi.org/10.1080/07294360.201 1.559195.

Ali, P. A., Watson, R., \& Dhingra, K. (2016). Postgraduate research students' and their supervisors' attitudes towards supervision. International Journal of Doctoral Studies, 11, 227-241. https://doi.org/10.28945/3541

Amrhein, H., \& Nassaji, H. (2010). Written corrective feedback: What do students and teachers prefer and why? Canadian Journal of Applied Linguistics, 13, 95-127.

Badenhorst, C., Moloney, C., Rosales, J., and Ru, L.(2015). Beyond deficit: Graduate student research-writing pedagogies, Teaching in Higher Education, 20(1), 1-11. https://doi.org/10.1080/13562517.2014.945160.

Basturkmen, H., East, M., \& Bitchener, J. (2014). Supervisors' on-script feedback comments on drafts of dissertations: socializing students into the academic discourse community, Teaching in Higher Education, 19(4), 432-445. https://doi.org/10.1080/13562517.2012.752728

Bitchener, J., Basturkmen, H., \& East, M. (2010). The focus of supervisor written feedback to thesis/dissertation students. International Journal of English Studies, 10(2), 79-97. https://doi.org/10.6018/ijes/2010/2/11920.

Bitchener, J., Basturkmen, H., East, M., \& Meyer, H. (2011). Best practices in supervisor feedback to thesis students. Research report. Ako Aotearoa .

Brown, H. D. (2007). Teaching by principles: An interactive approach to language pedagogy. Pearson Education.

Can, G., \& Walker, A. (2014). Social science doctoral students' needs and preferences for written feedback. Higher Education, 68(2), 303-318. https://doi.org/10.1007/s10734-014-9713-5.

Can, G., \& Walker, A. (2011) A Model for doctoral students' perceptions and attitudes toward written feedback for academic writing. Research in Higher Education, 52, 508-536. https://doi 10.1007/s11162-010-9204-1

Caterall, J., Ross, P., Aitchison, C., \& Burgin, S. (2011). Pedagogical approaches that facilitate writing in postgraduate research candidature in science and technology. Journal of University Teaching and Learning Practice, 8(2), Article 7.

Chen, S., Nassaji, H., \& Liu, Q. (2016). EFL learners' perceptions and preferences of written corrective feedback: a case study of university students from Mainland China. Asian Pacific Journal of Second and Foreign Language 
Education, 1(5), 1-17. https://doi10.1186/s40862016-0010-y.

Chokwe, J. M. (2015). Students' and tutors' perceptions of feedback on academic essays in an open and distance learning context. Open Praxis, 7(1), 39-56. https://doi.org/10.5944/openpraxis.7.1.154

Cotterall, S. (2011). Doctoral students writing: where's the pedagogy? Teaching in Higher Education, 16(4), 413425. https://doi.org/10.1080/13562517.2011.560381.

Esra, O. (2020).“I would like her to...:” ELT student-teachers' reflections on mentoring practices. PASAA: A Journal of Language teaching and learning, 59(1), 48-76.

Evans, N., Hartshorn, J., McCollum, R., \& Wolfersberger, M. (2010). Contextualizing corrective feedback in second language writing pedagogy. Language Teaching Research, 14 (4), 445-463. https://doi. org/10.1177/1362168810375367

Ferris, D. (2003). Response to student writing: Implications for second language students. Lawrence Erlbaum.

Ferris, D., \& Roberts, B. (2001). Error feedback in L2 writing classes: How explicit does it need to be? Journal of Second Language Writing, 10(3), 161-184. https://doi.org/10.1016/S10603743(01)00039-X

Ghandi, M., \& Maghsoudi, M. (2014). The effect of direct and indirect corrective feedback on Iranian EFL learners' spelling errors. English Language Teaching, 7, 53-61. https://doi.org/10.5539/elt.v7n8p53.

Ghazal, L., Gul, R, Hanzala, M., Jessop, T., \& Tharani, A. (2014) Graduate students' perceptions of written feedback at a private university in Pakistan. International Journal of Higher Education, 3(2), 13-27. https://doi. org/10.5430/ijhe.v3n2p13

Hattie, J., \& Timperley, H. (2007). The power of feedback. Review of Educational Research, 77(1), 81-112. https:// doi.org/10.3102/003465430298487

Heath, T. (2002). A quantitative analysis of PhD students' views of supervision. Higher Education Research Development, 21, 41-61. https://doi.org/10.1080/07294360220124648

Hoomanfard, M. H., Jafarigohar, M., Jalilifar, A., \& Hosseini Masum, S. M. (2018). A comparative study of graduate students' self-perceived needs for written feedback and the supervisors' perceptions. Journal of Research in Applied Linguistics, 9(2), 3-26. https://doi.org/10.1016/j.esp.2005.12.003

Hyland, K. (2009). Academic discourse. Continuum.

Katayama, A. (2007). Japanese EFL students' preferences toward correction of classroom oral errors. Asian EFL Journal, 9(4), 289-305. http://dx.doi.org/10.17507/tpls.0703.03

Kumar, V., \& Stracke, E. (2007). An analysis of written feedback on a PhD thesis. Teaching in Higher Education, 12(4), 461-470. https://doi.org/10.1080/13562510701415433

Lavelle, E., \& Bushrow, K. (2007). Writing approaches of graduate students. Educational Psychology, 27(6), 807822.

Lee, A. \& Murray, R. (2015) Supervising writing: helping postgraduate students develop as Researchers. Innovations in Education and Teaching International, 52(5), 558-570. https://doi.org/10.1080/14703297.2013. 866329.

Lee, I. (2004). Error correction in L2 secondary writing classroom. Journal of Second Language Writing, 13(4), 285312. https://doi.org/10.1016/j. jslw:2004.08.001

Lee, I. (2008). Student reactions to teacher feedback in two Hong Kong secondary classrooms. Journal of Second Language Writing, 17(3), 144-164. https://doi.org/10.1016/j.jslw.2007.12.001

Leng, K. (2014). An analysis of written feedback on ESL students' writing. Procedia - Social and Behavioral Sciences, 123, 389-397. https://doi.org/10.1016/j.sbspro.2014.01.1437.

Manjet, K. (2016). Graduate students' needs and preferences for written feedback on academic writing. English Language Teaching, 9(12), 79-88. https://doi.org/10.5539/elt.v9n12p79

Paré, A. (2011). Speaking and writing: Supervisory feedback and the dissertation. In L. McAlpine \& C. Amundsen (Eds.), Doctoral education: Research-based strategies (pp. 59-74). Springer. https://doi.org/10.1007/978-94007-0507-4_4

Pokorny, H. \& Pickford, P. (2010). Complexity cues and relationships: Student perceptions of feedback. Active\& Learning in higher Education, 11(1), 21-30. https://doi.org/10.1177/1469787409355872

Price, M., Handley, K., Millar, J., \& O’Donovan, B. (2010). Feedback: all that effort, but what is the effect? Assessment and Evaluation in Higher Education, 35(3), 277-289. http://dx.doi.org/10.1080/02602930903541007.

Rowe, A. (2009). The personal dimension in teaching: Why students value feedback. International Journal of Educational Managemen,t 25(4), 343-360. https://doi.org/10.1108/09513541111136630 .

Saeli, H. (2019). Teachers' practices and students' preferences: Grammar-centered written corrective feedback in Iran. Research in English Language Pedagogy, 7(1), 46-70. https://doi.org/10.30486/relp.2019.663422

Stracke, E., \& Kumar, V. (2010). Feedback and self-regulated learning: insights from supervisors' and PhD examiners' reports. Reflective Practice, 11(1), 19-32. http://dx.doi.org/10.1080/14623940903525140 


\section{YENUS NURIE}

Sutton, P. (2009).Towards dialogic feedback. Critical and Reflective Practice in Education, 1, 1-10. https://doi. org/10.1007/978-3-642-13166-0_27

Tee, P. L., Kumar, V., \& Abdullah, M. H. (2013). Written feedback on ESL student writers' academic essays. Pertanika Journal of Social Sciences and Humanities, 21(2), 477-502.

Vygotsky, L. (1978). The interaction between learning and development. In M. Cole, V. John-Steiner, S. Scribner \& E. Souberman (Eds.), Mind and Society (pp.79-91). Harvard University Press.

Wang, T., \& Jiang, L. (2015). Studies on written corrective feedback: Theoretical perspectives, empirical evidence, and future directions. English Language Teaching, 8(1), 110-120. http://dx.doi.org/10.5539/elt.v8n1p110.

Wang,T., \& Li,L.(2011). 'Tell me what to do'vs 'guide methrough it': Feedback experiences of international doctoral students. Active Learning in Higher Education, 12(2), 101-112. https://doi.org/10.1177/1469787411402438

Wang, P. (2010). Dealing with English majors' written errors in Chinese universities. Journal of Language Teaching and Research, 1(3), 194-205. http://dx.doi.org/10.4304/jltr.1.3.

Weaver, M. (2006). Do students value feedback? Students' perception of tutors' written responses. Assessment and Evaluation in Higher Education, 31(3), 379-394. https://doi.org/10.1080/02602930500353061

Yenus, N. (2018a). Higher education supervision practices on student thesis writing: Language function and focus of written feedback. International Journal of Teaching and Learning in Higher Education, 30(3), 1-12.

Yenus, N. (2018b). Doctoral students' perceived needs and preferences for supervisors' written feedback. PASAA, 56(2), 112-144.

Yin, K. (2011). Qualitative research from start to finish. Guilford Press.

Yinager, T. (2019). Views of summer TEFL postgraduate students and their supervisors on the practice of thesis supervision in the Ethiopian context. PASAA, 58 (2), 131-165.

Yu, S., \& Lee, I. (2013). Understanding supervisors' commentary practices in doctoral research proposal writing: A Hong Kong study. Asia-Pacific Education Researcher, 22(4), 473-483. https://doi.org/10.1007/s40299-0120046-9.

Zeleke A. (2017). Ethiopian public university entrants' writing skills in English language: The case of Hawassa University entrants. International Journal of Development Research, 7(9), 15089-15092.

Zewdu, E. (2012). An investigation into the research culture of Addis Ababa University: The case of a Teaching English as a Foreign Language (TEFL) PhD program [Doctoral

Dissertation]. Addis Ababa University. URL www.bdu.edu.et>bdu.edu.et.fh>files

Zhan, L. (2016). Written teacher feedback: student perceptions, teacher perceptions, and actual teacher performance. English Language Teaching, 9(8), 73-84. https://doi.org/10.5539/elt.v9n8p73 


\section{Appendix A}

\section{Questionnaire for Graduate Students}

The purpose of this questionnaire is to collect data on areas which you consider most important for you, and you want your advisor to look at. Therefore, your genuine response is useful for the completion of this study. The following are some postgraduate students' preferences towards supervisor feedback to thesis writing. Read each statement and then decide if you: (1) strongly disagree, (2) disagree,(3) neither agree nor disagree (undecided), (4) agree, or (5) strongly agree corresponding to the items provided.

Thank You

\begin{tabular}{|c|c|c|c|c|c|}
\hline When responding to my thesis, I want my advisor to comment on the: & 1 & 2 & 3 & 4 & 5 \\
\hline \multicolumn{6}{|l|}{ Content } \\
\hline \multicolumn{6}{|l|}{ Gaps in theoretical understanding and coverage } \\
\hline \multicolumn{6}{|l|}{ Gaps in the literature } \\
\hline \multicolumn{6}{|l|}{ Irrelevance of thesis } \\
\hline \multicolumn{6}{|l|}{ Wider significance the work } \\
\hline \multicolumn{6}{|l|}{ Gaps in the justification or explanation of arguments } \\
\hline \multicolumn{6}{|l|}{ Part-genre } \\
\hline \multicolumn{6}{|l|}{ Structure of what goes where and examples of what is expected } \\
\hline \multicolumn{6}{|l|}{ Purpose of part-genre } \\
\hline \multicolumn{6}{|l|}{ Part-genre Skills required for each genre } \\
\hline \multicolumn{6}{|l|}{ Expected word count from a thesis } \\
\hline \multicolumn{6}{|l|}{ Linguistic accuracy and appropriateness } \\
\hline \multicolumn{6}{|l|}{ Punctuation, spelling and capitalization } \\
\hline \multicolumn{6}{|l|}{ Systematic errors } \\
\hline \multicolumn{6}{|l|}{ Writing style } \\
\hline \multicolumn{6}{|l|}{ How to develop ideas with supportive and counter evidence } \\
\hline \multicolumn{6}{|l|}{ Writing coherence and cohesion and quality of writing } \\
\hline \multicolumn{6}{|l|}{ Grammar (verb tenses, subject/verb agreement, article use...etc.) } \\
\hline Appropriateness of vocabulary choice and academic register & & & & & \\
\hline
\end{tabular}




\section{YENUS NURIE}

\section{Appendix B}

Interview Questions for Graduate Students Answer the following questions by illustrating your points. I am only interested in understanding graduate students feedback needs to thesis writing.

1. Do you prefer that your supervisor provide you all types of content feedback? Why?

2. Which specific aspects of content feedback are the most important to you when your supervisor provides feedback to your thesis writing? Why?

3. Do you prefer that your supervisor provide you all types of genre feedback? Why?

4. Which specific aspects of genre feedback are the most important to you when your supervisor provides feedback to your thesis writing? Why?

5. Do you prefer that your supervisor provide you all types of linguistic feedback? Why?

6. Which specific aspects of linguistic accuracy feedback are the most important to you when your supervisor provides feedback to your thesis writing? Why?

7. In general, which feedback type among (feedback on content, genre or linguistic feedback) to thesis writing, do you like, your supervisor to provide you most? Why?

8. What are your expectations with respect to your supervisor feedback to your thesis writing? Why? 